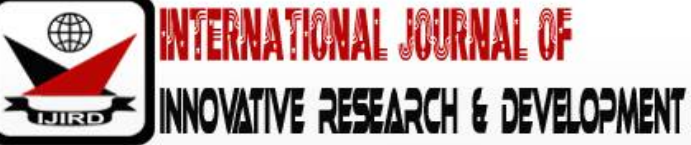

ISSN 2278 - 0211 (Online)

\section{The Influence of Social Networks on Students' Essay Writing: A Study of Selected Senior High Schools in the Cape Coast Metropolis, Ghana}

\author{
Abigail Oduro \\ Master Student, Beijing Normal University, China \\ Thomas Brefo \\ Student, Department of Arts Education, University of Cape Coast, Ghana \\ Dorcas Frempong Koranteng \\ Student, Department of Arts Education, University of Cape Coast, Ghana \\ Bertrand Azagsizua Abelumkemah \\ Student, Department of Arts Education, University of Cape Coast, Ghana
}

\begin{abstract}
:
The $21^{\text {st }}$ century has been described as a century of technological advancement since social networks are currently being used regularly by millions of people all over the world. The paper examined the influence of social networks on students' essay writing in English Language in selected Senior High Schools in the Cape Coast Metropolis. The descriptive survey design was adopted for the study. Questionnaires were used to gather relevant data from students at the Senior High Level. In all, 201 sample was selected for the study out of a population of 420 . The proportionate random sampling technique was used to collect samples from the selected schools. The study found out that Facebook, WhatsApp, Instagram, Imo, Twitter and Viber are the various social media networks available to students. It is worth mentioning here that there is a high level of students' participation in social media networks in Cape Coast Metropolis. It was recommended that teachers should be more vigilant on their students in order to monitor their use of phones and other electronic devices so that they can limit or regulate the time their wards spend on the various social media sites. English Language teachers should be critical on students' writing and should encourage students to read over their writings.
\end{abstract}

Keywords: Social media, essay writing and English language

\section{Introduction}

Social networks are currently being used regularly by millions of people; therefore, the $21^{\text {st }}$ century has been described as a century of technological advancement. This is due to fact that it is the century which is credited to making the world a global village. Social networks include a variety of web-based tools and services that are designed to promote community development through collaboration and information sharing (Arnold \& Paulus, 2010; Junko, Helbergert \& Loken, 2011).

Social media provides opportunities for individual expression as well as interaction with other users (Arnold \& Paulus, 2010). Social media networks include; Facebook, Twitter, Blogging, WhatsApp, Instagram, Imo and many others which were introduced in the early 2000 (Aida \& Egan, 2004). These social networks enable individuals to personally share, connect and interact with a list of other users who share the same connection with them and have played a crucial role in bridging boundaries and crossing the seas and enabling them to communicate on a common platform. An interesting aspect of social media is that it is not limited to desktop or laptop computers but could be accessed through mobile applications and smart phones making it very accessible and easy to use which has brought the world to a personal level. Understanding why students use online social media sites is crucial for the academic community, as this new communication platform exhibits its important impact on students' motivation to learn, affective learning, and classroom climate (Mazer, Murphy \& Simonds, 2007). Social media is cutting across all facets of society with its positive and negative influence in general. The social networking sites are gaining a lot of popularity these days with almost all of the educated youth using at least one of such sites. A number of studies have been conducted to find out the influence of social media on academic performance of students. Current research has indicated that using social media as an educational tool can lead to increased student engagement (Draper, Buil, Hernández-Ortega \& Sese, 2008). Nelson and Kuh (2005) also reported that students who use information technology for academics also have a higher likelihood of contributing and participating in active academic collaboration with other students. Among the vast variety of online tools which are available for communication, social network sites have become the most modern and influencing tool for connecting people throughout the world (Aghazamani, 2010). 
On the contrary, a study conducted by Karadkar (2015) indicates that social media networks affect students negatively because students spend more time on social media at the expense of their books. Also, other studies have found that social media negatively influence students' results as they spend as considerable time on social media rather than preparing adequately for class (Annetta, Minogue, Holmes \& Cheng 2009; Junco, 2012). Students neglect their studies by spending time on social media websites rather than studying or interacting with people in person (Karadkar, 2015). Actively and frequently participating in social media networks can negatively affect their grades or hamper their journey to their future carriers (Karadkar, 2015). Walsh (2013) wrote that students who spent the most time using social media had fewer academic behaviors such as completing homework and attending class, lower academic confidence and more problems affecting their schoolwork, like lack of sleep and substance use. According to the Internet Usage Statistics (2014), the penetration of internet on the African continent was $26.5 \%$. According to a survey conducted by PEW Research Center (2016), 72\% of high school students spend time on Facebook, Twitter, Instagram, WhatsApp among others (Internet World Statistics, 2015). By December 2012, the number of Facebook users in Africa was 51,612,460. In Ghana, the number of internet users as at June 2014, was 5,171,993 with 20\% internet penetration. Out of the total internet users in Ghana, 1,630,420 users were on Facebook, WhatsApp, Instagram among others (Internet World Statistics, 2015).

Ibrahim (2015), in a news report stated that social media has both positive and negative effects on Ghanaian youth. From the report, Ibrahim indicated that youth between the ages of 12 and 25 are most vulnerable to the negative impact of social media. Ibrahim stated in the report that Ghanaian youth spend long hours socializing and browsing the internet instead of concentrating on their academic work of which Senior High School students in Cape Coast are not an exception. The report attributed the issue as the probable reason why as many as $78 \%$ of the candidates who sat for the 2014 West African Senior School Certificate Examination (WASSCE) failed the exams. Ibrahim highlighted in the report that many of the candidates were writing social media-like type words instead of using standardized words. For instance, the article 'the' is written 'de', 'what' becomes 'wat' and 'you' turns into ' $u$ ' which is not accepted in formal writings. This observation has therefore necessitated this study to find out the impact of social networks on students' essay writing in English language.

\section{Statement of the Problem}

There have been a lot of debates on various platforms and media as to the impact that social media has on society and specifically its effects on students' academic performance. Some of these studies found a drop-in students' grades and academic performance and lack of time for studies as consequences of social media network participation (Banquil et al., 2009; Kirschner \& Karpinski, 2010; Ndaku, 2013). On the other hand, Pasket et al. (2006) stated that Facebook usage is not positively associated with lower grades of students but rather Facebook users score higher grades. Kolek and Saunders (2008) did not find any correlation between GPAs of student users and social network participation such as Facebook. Rather social networks sites promote interaction among students and teachers (Ahmed \& Qazi, 2011). Also, a study conducted by Horton, Alloway, and Dawson (2012) reveals that the use of Facebook has effect on the spelling of some students.

A number of studies in relation to social media have similarly been conducted in Ghana. These, however, have centered on social media use in basic schools (Amofah-Serwah \& Dadzie, 2015), and social media usage in tertiary level (Apeanti \& Danso, 2014). One study has looked at the time that students waste on social media networks at the neglect of their books which affect their academic performance (Banquil et al., 2009; Kirschner and Karpinski, 2010; Ndaku, 2013). Another study also did not find any correlation between GPAs of students and their social network participation such as Facebook (Kolek \& Saunders (2008). Also, the studies conducted by these researchers (Amofah-Serwah \& Dadzie, 2015; Apeanti \& Danso, 2014) were centered at the basic and tertiary levels. Since these studies have been conducted in basic schools and at tertiary levels, a gap has been created at the senior high levels. The researcher, therefore, finds it necessary to conduct this study to determine the influence of social media networks have on the academic performance of students in Senior High Schools, particularly their essay writing. It is therefore necessary to conduct this study to examine the influence of social media networks on students' essay writing.

\section{Objectives of the Study}

The general objective of the study of the study was to examine the influence of social networks on students' essay writing in selected Senior High Schools in the Cape Coast Metropolis. Specifically, the study set to find out:

- The various social media networks available to Senior High School students' in Cape Coast Metropolis.

- The level of Senior High School students' participation in the various social media networks.

- The effect of social networks on students' writing in English Language.

\section{Research Questions}

The three main questions the study sought to address are as follows:

- What are the various social media networks available to students in Senior High Schools in the Cape Coast Metropolis?

- What is the level of Senior High school students' participation in social media networks in Cape Coast Metropolis?

- What are the effects of social media networks on students writing? 


\section{Literature Review}

\subsection{Concept of Social Media}

Kaplan and Haenlein (2010) defined social media as a group of Internet-based applications that build on the ideological and technological foundations of Web, and that allow the creation and exchange of user generated content. Merriam-Webster (1961) also defines social media as forms of electronic communication (such as websites for social networking and micro blogging) through which users create online communities to share information, ideas, personal messages, and other content (such as videos).

In the views of Boyd and Ellison (2007), social networking sites are web-based services that allow individuals to construct a public or semi-public profile within a bounded system, articulate a list of other users with whom they share a connection, and view and traverse their list of connections and those made by others within the system. Helou and Rahim (2010) also define online social networks (OSNs) "as virtual communities which allow people to connect and interact with each other on a particular subject or to just hang out together online. Social media sites around the globe provide users with a number of options to interact with each other through entertainment, chats, gossips, and games. Through these social network platforms students are able to meet to interact with each other on various topics and interests.

Davis et al. (2012), refer to social media technology (SMT) as "web based and mobile applications that allow individuals and organizations to create, engage, and share new user generated or existing content in digital environments through multi-way communication. Popular social network platforms on mobile and web applications include Facebook, Twitter, YouTube, WhatsApp, Instagram, snap chat, Google Plus among others (Davis et al., 2012). These platforms have specific roles, functions and modes of communication although their functions are mostly related. This relates to the definition by Kaplan and Haenlein (2010), who view Social media as a group of Internet-based applications that build on the ideological and technological foundations and that allow the creation and exchange of user-generated content. Ayiah and Kumah (2011) summed up the definition of social network as a web platform where people from different settings can connect and interact with each other. A critical look at the research conducted on Social Network sites, reveals certain information which is crucial to issues regarding social media sites. Boyd and Ellison (2006) further define social networking sites as having three common elements: a member profile (in their definition this is always a web page); the ability to add other members to a contact list (the names of your contacts vary - they might be called friends or buddies, for example); and supported interaction between members of contact lists (interaction varies greatly, and there will typically be some degree of interaction facilitated between people who are not named contacts). They further opine that the most popular dedicated social network sites in the UK are MySpace, Facebook and Bebo. These types of SNS are profile focused - activity centers on web pages that contain information about the activities, interests and likes (and dislikes) of each member (Boyd \& Ellison, 2006). Researchers argue that the impact of social media relies on the fact that they employ mobile and web-based technologies to create highly interactive platforms via which individuals and communities share, create and co-create, discuss, and modify user generated Content (Ahlqvist, 2008). Piskorski (2011) argues that the secret of successful ones and here he refers to the business rather than the social success-is that they allow people to fulfill social needs that either cannot be met offline or can be met only at much greater cost. This insight provides another perspective on social media: it does help not only social communication, but also the business world. It implies that companies can leverage social platforms to create a sustainable competitive advantage. Companies need to help people interact with each other before they will promote products to their friends or help companies in other ways.

From the definitions given by various scholars, it can be observed that two key basic things run through all their definitions: social media being electronic or online or web-based system and that it connects people and enables them to share contents or resources and interact with one another.

\subsection{Types of Social Media Networking Sites}

Different scholars have tried to identify types of social networking sites. Notably among the types identified by scholars are:

\subsubsection{Profile-Based Social Networking Sites}

Ayiah and Kumah (2011) defineProfile-based social networking sites as services which are primarily organised around members 'profile pages'. Boyd and Ellison (2006) gave Bebo, Facebook and MySpace, are all good examplesof Profile-based social networking sites. Users develop their space in various waysand can often contribute to each other's spaces - typically leaving text, embedded content or links to external content through message walls, comment or evaluation tools.

Users often include third party content (in the form of 'widgets') in order to enhance their profiles, or as a way of including information from other web services and SNS (Boyd \& Ellison, 2006).

\subsubsection{Content-based SNS}

In these services, the user's profile remains an important way of organising connections, but play a secondary role to the posting of content (Kaplan \& Heinlein, 2010). Kaplan and Heinlein (2010) gave Photo-sharing site Flickr is an example of this type of service, one where groups and comments are based around pictures. There are many people of course who have 'empty' Flickr accounts - people who have signed up to the service in order to view their friends' or families' permission protected pictures (Kaplan \& Heinlein, 2010). According to Ayiah and Kumah (2011), Shelfari is one of the current crops of book-focused sites, with the members bookshelf' being a focal point of their profile and membership. Other examples of content-based communities include YouTube for video-sharing and, where the content is 
created by software that monitors and represents the music that users listen to. In the latter case, the content is primarily the user's activity - the act of listening to audio files (Ayiah \& Kumah, 2011).

\subsubsection{Multi-User Virtual Environments}

Sites such as Second Life, an online virtual world, allow users to interact with each other's avatars - a virtual representation of the site member (Boyd \& Ellison, 2006). Although the users have profile cards, their functional profiles are the characters they customise or build and control. According to Boyd and Ellison (2006) there are also hybrids of these and social-networking sites, such as Habbo Hotel and Cyworld.

\subsubsection{Mobile SNS}

According to Boyd and Ellison (2006) many social network sites such as MySpace and Twitter, Facebook, WhatsApp, Instagram among others offer mobile phone versions of their services, allowing members to interact with their networks via their phones. Increasingly, too, there are mobile-led and mobile-only based communities. MYUBO for example, allows users to share and view video over mobile networks (Boyd \& Ellison, 2006).

\subsubsection{Micro-Blogging/ Presence Updates}

Micro-blogging services such as Twitter and Jaiku allow you to publish short (140 characters, including spaces) messages publicly or within contact groups (Boyd \& Ellison, 2006).According to Ayiah and Kumah (2011), these social networking sites are designed to work as mobile services, but are popularly used and read online.

Many services offer 'status updates' - short messages that can be updated to letpeople know what mood you are in or what you are doing. These can be checked within the site or exported to be read elsewhere. They engage users in constantly updated conversation and contact with their online networks (Boyd \& Ellison, 2006).

\subsubsection{People Search}

People search is another important web development. According to Kaplan and Heinlein (2010), there are various kinds of social and people search, but sites like 'Wink'generate results by searching across the public profiles of multiple social network sites. This allows search by name, interest, location and other information published in profiles, allowing the creation of Web-based "dossiers" on individuals. This type of people searches cuts across the traditional boundaries of social network site membership, although the data that are retrieved should already be public (Boyd \& Ellison, 2006).

Thus, social media performs different roles depending on the user and the type of social media he or she subscribes to. Accordingly, scholars have therefore categorised social media into profile based, content based, people search, mobile SNS, Micro-blogging/ Presence updates and Multi-User Virtual Environments.

\subsection{The Influence of Social Media}

The online English dictionary defines 'influence' as the power to affect, control or manipulate something or someone. Or, it is the ability to change the development of fluctuating of things such as conduct, thoughts or decisions. The English thesaurus identifies the words 'impact,' 'effect,' and 'power' as being synonymous with 'influence,' therefore, 'influence,' 'impact' and 'effect' will be used interchangeably in this paper. From the above definitions, the concept 'social media,' can therefore be referred to us the ability or the power of social media to control, or manipulate its users, positively or negatively. Thus, it can be seen as the impact or effect of social media on people or things. The influence, as noted above, can be both positive and negative. The influence of social media in this paper is hence presented in two perspectives: positive influence and negative influence.

As regards positive influence, Chakravarty (2017), discussing the influence of social media on teenagers and students, noted that social media helps students develop awareness about their world and society; it helps them acquire social skills as they interact and make friends. She further noted that social media particularly helped students develop reading and writing skills through blogs, chat room among others. In an article by Millicent Mensa on modern Ghana (2016, October 14) also claimed that social media informs students about educational opportunities available to them including educational institutions, scholarships and sponsorships. Ibrahim F. (2014, September 15) in an article on modern Ghana also purported that through the influence of social media, students are able to get help on academic and related issues on various social forums which help them have access to basic research for assignments. The point made here is that social media is playing a crucial role in the life of students, particularly its role in developing reading and writing skills of student. Thus, social media has a positive impact on students as far as the above views are concerned.

On the other hand, much more have been said about the negative influence of social media on students' life. In fact, the views of Karadkar (2015) are worth acknowledging here:

The most important things in a student's life are studying, learning good habits and gaining knowledge to become a person with moral character. But today, this optimal learning process is seriously jeopardized by students becoming entrapped by the ploys of social networking. Students neglect their studies by spending time on social networking websites rather than studying.

Actively and frequently participating in social networking can negatively affect their grades or hamper their journeys to their future careers. It is obvious from this excerpt that Karadkar views the downside of social media as far outweighing its merits on students. Similarly, a Ghanaian Deputy Minister of Education, Mr. Okudjeto Ablakwa said social media was negatively affecting the writing and speaking of English language among students in the country, especially those in the Senior High School (SHS) level ("Social media affect writing and speaking of English," 2014). According to him, students are transferring their ways of writing on social media platforms into the examination rooms. His view was joined 
in by a Ghanaian ex President, Mr. John Agyekum Kuffour, who lamented that though social media has played good roles in the lives of Ghanaians, it is now having negative implications especially with the youth("Social media has negative implications," 2016). Also, according to modernghana.com, Ibrahim F. (2014, September 15) drew a link between the 78\% failure in 2014 WASSCE of Ghanaian candidates and social media, as candidates were reported to have written social media type of words like 'de,' 'wat,' and; u' in their exam. The conclusion to be drawn here, considering the above arguments, is not to deny the positive impact or role social media plays in the educational life of the Ghanaian students. What, however, is significant noting here is that much as social media has a potential of developing the reading and writing skills of students, among others, it as well massively inhibits the writing skills of students, which has an enormous potential of marring their academic developing and career as it leads to their failure in academic especially.

\subsection{Social Media Networks Available to Students}

Mingle and Adams (2015) conducted a study to look at social media network participation and academic performance in Senior High Schools. The study was aimed at identifying social media network sites and their usage among students. To achieve the objectives of the research, the study used a mixed method approach which involved the survey of students in four Senior High Schools and interviews of heads of the senior high schools. The study revealed that majority of respondents used WhatsApp and Facebook for making friends and chatting. In addition, majority of respondents experienced negative effects such as poor grammar and spelling, late submission of assignment, less study time and poor academic performance due to the heavy participation on social media networks. Furthermore, there was a high addiction rate among students in the usage of social media networks.

Nevertheless, there were cases where others experienced improvement in their readings skills as a result of participation on social media networks. Also, respondents shared ideas, discussed and shared examination questions among themselves on social media networks. The study recommended the strict enforcement of Ghana Education Service rule on electronic devices usage in schools, promotion of social media usage for academic purpose, counseling for addicted students and the use of the right grammar and spelling when participating on social networks. However, in their study, they used a mixed method approach which involved the survey of the students in four Senior High Schools and interviewed the heads of the Senior High Schools but our research will focus on only the students. It will also be conducted in two Senior High Schools. Also, their studies focused on only WhatsApp and Facebook but our studies consider more than two social media networks.

Another study conducted by Cheung, Chu, and Lee (2011), was aimed at determining how the growth and popularity of online social networks such as, Facebook, WhatsApp, and twitter among others has created a new world of collaboration and communication. More than a billion individuals around the world are connected and networked together to create, collaborate and contribute their knowledge and wisdom. Despite the importance of online social networks, there is a relatively little theory on empirical research available to address this type of communication and interaction phenomenon. In their paper, they talked about the various social media sites, explained the factors that drive students to use online social networks as international social action and examined the relative impact of social influence and the five key values from the uses and gratification paradigm on 'We- interaction' to use online social networks. Their research focused on some of the social media networks, but our research will focus on all the available social media networks and their influence on students' writing.

\subsection{Level of Senior High School Students' Participation in Social Media}

Researchers with interest in education have conducted research on social media and its effects on students writing. One study in this respect is Junco (2011) whose research was conducted on college students. The study examined the relationship between frequency of Facebook use, participation in Facebook activities, and student engagement. Students' engagement was measured in three ways: a 19-item scale based on the National Survey of Student Engagement, time spent preparing for class, and time spent in cocurricular activities, in the United States of America. The results indicated that Facebook use was significantly negatively predictive of engagement scale score and positively predictive of time spent in co-curricular activities. However, this study fills the gap in the literature by using the descriptive survey to examine the effects of social media on some selected senior high students' essay writing in Ghana.

A similar study was conducted by Flad (2010) whose study was conducted to measure and to assess the amount of time the average High School student would spend on social networking websites, whether or not these activities were impacting their grades and school work, and how important social networking was to them as compared to their academics. His study which was conducted in the United States of America used the survey method in a population of 1,500 high students, consisting of tenth, eleventh and twelfth grades. The results indicated that $39 \%$ of participants admitted to having membership to one social network site, $49 \%$ had membership on two and $12 \%$ responded to having membership to three or more social network sites. In terms of frequency, ranging from never visiting a social network site to accessing a network site more than five times each day,56\% reported to visiting their network site at least once per day, $29 \%$ visited their network sites more than five times per day. In effect, the study found that majority of the students spent more time on social media sites rather than doing their assignment or studying. This study therefore fills the gap in the literature by conducting the study in Ghana high schools using a lesser population.

In another research conducted by Mingle and Adams (2015), they sought to identify social media network sites and their usage among students, how students networked and participated on social media networks, time invested by students on social network participation on students' academic performance within the context of the social learning and the use and gratification theories. Their study used a two-method approach: a survey of students and interviews of the heads of the senior high schools. The study found that a majority of respondents used WhatsApp and Facebook for making 
friends and chatting. Also, the study also revealed that majority of the respondents experienced negative effects such as late submission of assignment, less study time and poor academic performance primarily due to heavy participation as well as high addiction rate of social media networks. This study fills the gap in the literature by examining the effects of the students' participation on their essay writing.

\subsection{How Students' Usage of Social Network Affects their Spelling.}

A number of researches have been conducted on students' usage of social media and their spelling. A study conducted by Thurairaj, Hoon, Roy and Wei Fong (2015) in Malaysia identified that Social networking sites (SNSs) have become a major form of communication in today's day and age whereby language use has been impacted in various areas especially in that of learning and teaching. Young users use literally half their week engaging in SNSs communication, thereby giving rise to a brand of internet slang which is entirely their own. The questions asked in the survey increased the identification of the linguistic features such as the frequency of code switching and erratic spelling thus expanding the research base. The survey participants, the majority of who are from the Chinese ethnic group had experienced mother tongue interference in their English Language proficiency. The descriptive statistical method was used to analyse the questionnaires, wherein the data collected indicated a rather excessive usage of short messaging texts by almost all respondents owning a mobile device. To authenticate the research findings, an analysis of the text discourses was found to be necessary. The findings proved that the frequent use of short messaging had not majorly affected the English language proficiency of the participants. In academic writing, there was a conscious effort to steer clear of SNSs language. The mushrooming SNSs has helped create a whole young generation who have their own meta-language, which provides an opportunity to probe to what extent the English language is altered.

From this study, it is clear that social media affects students in a way but the researcher failed to give any hint about how these social media participations by students affects their writing in the academia. Also, the study was conducted in Malaysia and also was conducted using Chinese English speakers. The study was also conducted at the tertiary level which creates a gap at the Senior High School level.

Another research conducted by Yeboah and Ewur (2011) also sought to empirically identify the impact of social network (WhatsApp messenger) on the performance of tertiary students in Ghana from the perspective of the students. To achieve this, 50 students from five tertiary institutions were interviewed and 500 questionnaires were administered to students from same institutions. The study revealed that, WhatsApp instead of making communication easier and faster thereby enhancing effective flow of information and idea sharing among students, rather has impacted negatively on the performance of tertiary students in Ghana. The study among other things unveiled the following: WhatsApp takes much of students' study time, results in procrastination related problems, destroys students' spellings and grammatical construction of sentences, leads to lack of concentration during lectures, results in difficulty in balancing online activities (WhatsApp) and academic preparation, and distracts students from completing their assignments and adhering to their private studies time table.

\section{Research Methodology}

The study design was descriptive survey. The sole purpose of descriptive research is to provide an accurate and valid representation of the factors or variables that are relevant to the research question (Amedahe, 2002).Descriptive survey research is helpful in indicating trends in attitudes and behaviors and enables generalization of the findings of the research study to be done (Neuman, 2000). Gay (cited in Oppong, 2009) contends that the descriptive design befits educational investigations including evaluation or assessment of attitudes, opinions, demographic information, conditions and procedures. Therefore, the descriptive survey will be an appropriate design for the exploration of the influence of social networks on Senior High Students' essay writing in English Language.

According to Fink (cited in Oppong, 2009), the design also enables the researcher to describe, observe and document aspects of a situation as it naturally occurs rather than explaining it. It enables the researcher to produce a good amount of responses from a wide range of people. Several writers (Sarantakos, 1998; Creswell, 2002) point out that, data gathered with such a design provides a more accurate picture of events and seeks to explain people's perception and behaviour on the basis of data gathered at a point in time. Despite the merits of the descriptive survey, Kelley, Clark, Brown and Sitzia (2003), pointed out some demerits associated with its use. These include the danger that the significance of the data can become neglected. This, according to them, happens if the researcher focuses too much on the range of coverage to the exclusion of an adequate account of the implications of those data for relevant issues, problems, or theories. Also, descriptive survey may delve into the private affairs of respondents and therefore create the likelihood of generating unreliable responses and difficulty in assessing the clarity and precision of questions that elicit the desired responses (Fraenkel \& Wallen, 2000).

The target population for the study comprised all third-year students offering English Language in the selected Senior High Schools in the Cape Coast Metropolis. However, the accessible population was made up of all third year General Arts students in the two selected Senior High Schools. The schools that were selected include: Adisadel College and University Practice Senior High Schools. In these schools, the population of all third year General Arts students available was 420 .

The sample size for the study was 201 . The sample size selection was influenced by the guidelines provided by Krejcie and Morgan's (1970). According to Krejcie and Morgan's (1970), a population of 420 should select a sample size of 201. These are the sample size for each school: Adisadel College, 124 and University Practice Senior High School, 77. This is in line with Krejcie and Morgan's (1970) table for choosing sample size with an accessible population of 420, a sample size of 201 was chosen for the study. The study used questionnaires as the instrument for the data collection. 
Questionnaire prove to be easy to standardize, because in questionnaire respondents are asked the same questions in the same way (Creswell, 2002). Data collected were analyzed with the quantitative analytical procedures. The quantitative analysis took the form of descriptive statistics such as frequencies, percentages, means and standard deviations with the aid of the Statistical Product Solution (SPSS) version 16.0.

\section{Results and Discussion}

The background characteristics considered in this study were gender and age. Frequency and percentages were the analytical tools used for the background characteristics as shown in tables 1 and 2.

\begin{tabular}{|c|c|c|}
\hline Sex & Frequency & Percentage \\
\hline Male & 149 & 76.4 \\
\hline Female & 46 & 23.6 \\
\hline Total & 195 & 100.0 \\
\hline \multicolumn{2}{|c|}{ Table 1: Sex Distribution of Respondents } \\
Source: Field survey, 2018
\end{tabular}

Regarding the background features it can be viewed from Table 1, for instance, that the majority (76.4\%) of the respondents were male students whilst $(23.6 \%)$ of the respondents were female students. This means that more male students were involved in the study than female students.

\begin{tabular}{|c|c|c|}
\hline Age (Year) & Frequency & Percentage \\
\hline $15-20$ & 194 & 99.5 \\
\hline $21-26$ & 1 & 0.5 \\
\hline Total & 195 & 100.0 \\
\hline
\end{tabular}

It is also revealing from Table 2 that majority (99.5\%) of the respondents were between 15-20years and (0.5\%) were between 21-26years. This implies that majority of the students who were involved in the study were between 1520years. With respect to the various social media networks available to students in the Senior High Schools in the Cape Coast Metropolis, showed in Table 3. It was that (30.8\%) of the students used Facebook, $(23.0 \%)$ used WhatsApp and $(14.4 \%)$ used Instagram. Following the results closely, it can be observed that (12.8\%) of the students used Imo, $(10.3 \%)$ used Twitter and (8.7\%) used Viber. This agreed with Mingle and Adams (2015) which revealed that majority of students used WhatsApp and Facebook for making friends and chatting. Furthermore, there was a high addiction rate among students in the usage of social media networks. Billions of individuals around the world are connected and networked together to create, collaborate and contribute their knowledge and wisdom (Cheung, Chu, and Lee, 2011). This means that there was growth and popularity of online social networks such as, Facebook, WhatsApp, twitter among others.

\begin{tabular}{|c|c|c|}
\hline Various Social Media Networks & N & Percentage (\%) \\
\hline Facebook & 60 & 30.8 \\
\hline WhatsApp & 45 & 23.0 \\
\hline Imo & 25 & 12.8 \\
\hline Instagram & 28 & 14.4 \\
\hline Twitter & 20 & 10.3 \\
\hline Viber & 17 & 8.7 \\
\hline Total & 195 & 100 \\
\hline
\end{tabular}

Table 3: Various Social Media Networks Available to Students

Source: Field survey, 2018

Again, when the respondents were asked of their level of participation in social media networks as shown in table 4. The results indicated that most of the students agreed that they often visit social media sites and their response differ much from each other $(\mathrm{M}=3.98 ; \mathrm{SD}=1.19)$. Following the responses of the students on the statement that solicited their responses on the fact that they have used social media network for more than six months, the results revealed that majority of them strongly agreed and there existed differences in their responses ( $M=4.17 ; \mathrm{SD}=1.21)$. In addition, the results showed that majority of the students agreed that they often get surprised by how much time they have spent on social media and there were many differences in their responses $(M=3.50 ; S D=1.34)$. Furthermore, the results depicted that majority of the students disagreed that they cannot stay away from social media for more than an hour and their responses did differ much from each other on the statement $(\mathrm{M}=2.27 ; \mathrm{SD}=1.32)$. Finally, the results disclosed that most of the students disagreed that they often stay up late to spend more time on social media networks and there were many distinctions in their responses concerning the statement $(\mathrm{M}=2.99 ; \mathrm{SD}=1.45)$. The overall mean and standard deviation values of the level of senior high school students' participation in social media networks in Cape Coast Metropolis rated 3.38 and 1.30 respectively. This implies that majority of the students agreed on the statements that solicited their responses on the level of senior high school students' participation in social media networks in Cape Coast Metropolis and 
there were no much variations concerning their responses. From the responses of the students on the level of senior high school students' participation in social media networks in Cape Coast Metropolis, it can be said that there is a high level of students' participation in social media networks in Cape Coast Metropolis. This is evident from the results as majority of them agreed that they often visit social media sites, they have used social media network for more than six months and they often get surprised by how much time they have spent on social media.

\begin{tabular}{|c|c|c|}
\hline \multirow{2}{*}{ Level of Participation in Social Media Networks } & \multicolumn{2}{|c|}{ Students (n=195) } \\
\cline { 2 - 3 } & Mean & $\begin{array}{c}\text { Standard } \\
\text { Deviation }\end{array}$ \\
\hline I often visit social media sites & 3.98 & 1.19 \\
\hline I have used social media network for more than six months & 4.17 & 1.21 \\
\hline I often get surprised by how much time I spend on social media & 3.50 & 1.32 \\
\hline I cannot stay away from social media for more than an hour & 2.27 & 1.32 \\
\hline I often stay up late to spend more time on social networks & 2.99 & 1.45 \\
\hline Total & 3.38 & 1.30 \\
\hline
\end{tabular}

Table 4: Level of Senior High School Students' Participation in Social Media Networks Source: Field survey, 2018

The above findings corroborate the findings of Flad (2010) on the amount of time the average high school student would spend on social networking websites, whether or not these activities were impacting their grades and schoolwork, and how important social networking was to them as compared to their academics. The results indicated that $39 \%$ of participants admitted to having membership to one social network site, $49 \%$ had membership on two and $12 \%$ responded to having membership to three or more social network sites. In terms of frequency, ranging from never visiting a social network site to accessing a network site more than five times each day, $56 \%$ reported to visiting their network site at least once per day, $29 \%$ visited their network sites more than five times per day.

Table 5presents the responses of students on the effects of social media networks on students' writing. With regard to students paying little attention to the use of punctuation marks just as they do in social media communications, it was revealed that majority of the students strongly agreed with the statement and their responses differ much from each other concerning the statement $(\mathrm{M}=4.11 ; \mathrm{SD}=1.20)$. With reference to the responses of the students on the statement that students subconsciously use shorthand in their writing, it revealed that majority of the respondents strongly agreed to the statements and their responses differ much from each other concerning the statement $(\mathrm{M}=4.31 ; \mathrm{SD}=1.03)$. For their responses on students subconsciously or unintentionally using jargons or slangs in their writing, the results showed that majority of the respondents agreed with the statement and their responses differ much from each other concerning the statement $(\mathrm{M}=3.93$; $\mathrm{SD}=1.15)$. Following the responses of the students the use of shorthand in social media communication making chatting easier and faster, the result showed that majority of the respondents strongly agreed with the statement and their responses did not differ much from each other concerning the statement $(\mathrm{M}=4.51 ; \mathrm{SD}=0.87)$.

Another indicator to measure the effects of social media networks on students' writing was students' poor essay writing habit is partly due to the introduction of social networks rather than the writing of letters. On the basis of that the results showed ( $\mathrm{M}=3.69 ; \mathrm{SD}=1.36$ ). This logically implies that majority of the respondents agreed with the statement and their responses differ much from each other concerning the statement. Finally, it can be observed from the results that majority of the students agreed that students' poor performance in essay writing can partly be attributed to social media network usage with much variations in their responses $(\mathrm{M}=3.48 ; \mathrm{SD}=1.42)$. The overall mean and standard deviation values of the responses of students on effects of social media networks on students' writing. 4.00 and 1.17 respectively. This implies that majority of the students strongly agreed to the statements soliciting their responses on the effects of social media networks on students' writing in the Cape Coast Metropolis and their responses differ much from each other concerning the statements.

\begin{tabular}{|c|c|c|}
\hline & \multicolumn{2}{|c|}{ Students (n=195) } \\
\cline { 2 - 3 } Effects of Social Media Networks on Students Writing & Mean & Standard Deviation \\
\hline $\begin{array}{c}\text { Students pay little attention to the use of punctuation marks just as } \\
\text { they do in social media communications }\end{array}$ & 4.11 & 1.20 \\
\hline $\begin{array}{c}\text { Students subconsciously use shorthand in their writing } \\
\text { their writing }\end{array}$ & 4.31 & 1.03 \\
\hline $\begin{array}{c}\text { Students subconsciously or unintentionally use jargons or slangs in } \\
\text { chatting easier and faster }\end{array}$ & 3.93 & 1.15 \\
\hline $\begin{array}{c}\text { The use of shorthand in social media communication makes } \\
\text { chath }\end{array}$ & 4.51 & 1.36 \\
\hline $\begin{array}{c}\text { Students' poor essay writing habit is partly due to the introduction } \\
\text { of social networks rather than the writing of letters }\end{array}$ & 3.69 & 1.42 \\
\hline $\begin{array}{c}\text { Students' poor performance in essay writing can partly be } \\
\text { attributed to social media network usage }\end{array}$ & 3.48 & 1.17 \\
\hline Total & 4.00 & \\
\hline
\end{tabular}

Table 5: The Effects of Social Media Networks on Students' Writing Source: Field survey, 2018 
From the above responses of the students, it can be established that social media networks have affected students; academic writing by; making students to pay little attention to the use of punctuation marks just as they do in social media communications, making students subconsciously use shorthand in their writing and making students to subconsciously or unintentionally use jargons or slangs in their writing. Other effects of social media networks on students; academic writing was tallied as; students' poor essay writing habit is partly due to the introduction of social networks rather than the writing of letters and students' poor performance in essay writing can partly be attributed to social media network usage.

\section{Conclusions and Recommendations}

The researchers observed that Facebook, WhatsApp, Instagram, Imo, Twitter and Viber are the various social media networks available to students. It is worth mentioning here that there is a high level of students' participation in social media networks in Cape Coast Metropolis. Evidently, majority of them agreed that they often visit social media sites, they have used social media network for more than six months and they often get surprised by how much time they have spent on social media. Finally, we conclude that social media networks have affected students' academic writing by; making students to pay little attention to the use of punctuation marks just as they do in social media communications, making students subconsciously use shorthand in their writing and making students to subconsciously or unintentionally use jargons or slangs in their writing. Other effects of social media networks on students' academic writing were tallied as; students' poor essay writing habit is partly due to the introduction of social networks rather than the writing of letters and students' poor performance in essay writing can partly be attributed to social media network usage.

The study recommends that Parents should be more vigilant on their wards in order to monitor their use of phones and other electronic devices so that they can limit or regulate the time their wards spend on the various social media sites. Also, teachers should be more vigilant on their students in order to monitor their use of phones and other electronic devices so that they can limit or regulate the time their wards spend on the various social media sites. Secondly, Heads of Senior High Schools should organise regular mass education or talks in all Senior High Schools in the country. Such talks should be based on the negative effects of social media on students' academic work. This awareness will help students use social media sites responsibly and positively. In addition, English Language teachers should be critical on students' writing and should encourage students to read over these writings. Defaulters should be punished accordingly.

\section{References}

i. Aghazamani, A. (2010). How do university students spend their time on Facebook? An exploratory study. Journal of American Science, 6(12), 730-735.

ii. Ahlqvist, B. S. (2008). Social media? Get serious! Understanding the functional building blocks of social media. Business horizons, 54(3), 241-251.

iii. Ahmed, I., \& Qasi, T. F. (2011). A look out for academic impact of social networking sites: a student-based perspective. African journal of business management, 5(12), 5022-5031.

iv. Ahn, J. (2011). The effect of social network sites on adolescents' social and academic development: Current theories and controversies. Journal of the American Society for Information Science and Technology, 8(62), 14351445.

v. Aida, E. F., \& Egan, K. (2004). The differences between Facebook, twitter, linkedin, google, youtube and pinterest. Retrieved from https:// www.impactbnd.com/blog/the-difference-between-facebooktwitter-linkedin-googleyoutube-pinterest

vi. Amedahe, F. K. (2002). Fundamentals of educational research methods. Cape Coast: University of Cape Coast Press.

vii. Amofah-Serwaa, N., \& Dadzie, P. S. (2015). Social media use and its implications on child behaviour: A study of a basic school in Ghana. International journal of social media and interactive learning environments, 3(1), 49-62.

viii. Annetta, L. A., Minogue, J., Holmes, S. Y., \& Cheng, M. T. (2009). Investigating the impact of video games on high school students' engagement and learning about genetics. Computers and Education, 53(1), 74-85.

ix. Apeanti, W. O., \& Danso, E. D. (2014). Students' use of social media in higher education in Ghana. Innovative Journal, 3(1), 3-9.

x. Arnold, N., \& Paulus, T. (2010). Using a social networking site for experiential learning: Appropriating, lurking, modeling and community building. The Internet and Higher Education, 13(4), 188-196.

xi. Ayiah, E. M., \& Kumah, C. H. (2011). Social networking: A tool to use for effective service delivery to clients by African libraries. World Library and Information Congress: 77th IFLA General Conference and Assembly (pp. 114).

xii. Banquil, K., Chua, N. A., Leano, G. A., Rivero, M. A., Burce, C. A., Dianalan, S. A., \& Timog, N. U. (2009). Social networking sites affect one's academic performance adversely. UST College of Nursing, 1-42.

xiii. Boyd, D. M. \& Elisson, N. B. (2007).Social network sites: Definition, history, and scholarship. Journal ofComputerMediated Communication, 1(13), 11-16

xiv. Davis, C. H. F., Canche, M. S. G., Deil-Amen, R. \& Rios-Aguilar, C. (2012). Social media in higher education: A literature review and research directions. Arizona: The Center for the Study of Higher Education at the University of Arizona and Claremont Graduate University.

xv. Draper, L., Buil, I., Hernández-Ortega, B., \& Sese, F. J. (2008). Using clickers in class: The role of interactivity, active collaborative learning and engagement in learning performance. Computers and Education, 6(2), 102-110. 
xvi. Flad, T. (2010). What is a flag for? Social media reporting tools and the vocabulary of complaint. New Media and Society, 18(3), 410-428.

xvii. Fraenkel, J. R., \& Wallen, N. E. (2000). How to design and evaluate research in education (4th ed.).Boston: McGraw Hill.

xviii. Helou, A. M., \& Rahim, N. Z. A. (2014). The influence of social networking sites on students' academic performance in Malaysia. International Journal of Electronic Commerce, 5(2), 247-254.

xix. Ibrahim, S. B. (2015). Power, social influence, and sense making: Effects of network centrality and proximity on employee perceptions. Administrative Science Quarterly, 3(8), 277-303.

xx. Internet World Statistics (2014). Usage and population statistic. Retrieved April 12, 2017 from internetworldstats.com/ stats1.htm.

xxi. Ito, M., Baumer, S., Bittanti, M., Boyd, D., Cody, R. and Herr-Stephenson, B. (2009). Hanging out, messing around, and geeing out: Kids living and learning with new media. Cambridge: MT Press.

xxii. Junco, R. (2012). Too much face and not enough books: The relationship between multiple indices of Facebook use and academic performance. Computers and Education 2(8), 187-198.

xxiii. Junko, H., Helbergert, E. L., \& Loken, R. R. (2011). Handbook of disaster research. New York: Springer.

xxiv. Kaplan, A. M., \& Haenlein, M. (2010). Users of the world, unite: The challenges and opportunities of social media. Business Horizons 5(3), 59-68.

xxv. Karadkar, S. (2015). Rethinking media and disasters in a global age: What's changed and why it matters. Media, War and Conflict, 7(1), 3-22.

xxvi. Kelley, K., Clark, B., Brown, V., \& Sitzia, J. (2003). Good practice in the conduct and reporting of survey research. International Journal for Quality in Health Care, 15(3), 261-266.

xxvii. Kirschner, P. A., \& Karpinski, A. C. (2010). Facebook and academic performance. Computers in human behaviour, 26(6), 1237-1245.

xxviii. Kolek, E. A., \& Saunders, D. (2008). Online disclosure: An empirical examination of undergraduate Facebook profiles. NASPA Journal, 45(1), 1-25.

xxix. Krejcie, R., \& Morgan, D. W. (1970). Determining sample size for research activities. Educational and Psychological Measurement, 30, 607-610.

xxx. Mazer, J. P., Murphy, R. E., \& Simonds, C. J. (2007). I'll see you on Facebook: The effects of computer-mediated teacher self-disclosure on student motivation, affective learning, and classroom climate. Communication Education, 56(1), 1-17.

xxxi. Mehmood, S., \& Taswir, T. (2013). The effects of social networking sites on the academic performance of students in college of applied sciences. International Journal of Arts and Commerce, 2(1), 111-125.

xxxii. Merriam-Webster, K. R. (2012). Somebody poisoned the jury pool: Social media's effect on jury impartiality. Wesleyan Literature. Review, 1(9), 809-815

xxxiii. Mingle, J., \& Adams, M. (2015). Social media network participation and academic performance in senior high schools in Ghana. Library Philosophy and Practice, 1(2), 2-10.

xxxiv. Ndaku, A. J. (2013). Impact of social media on students' academic performance: A study of students of University of Abuja. Unpublished project work, Caritas University, Enugu, Nigeria.

xxxv. Nelson, T. F. N., \& Kuh, G. D. (2005). Student experiences with information technology and their relationship to other aspects of student engagement. Research in Higher Education, 46(2), 211-233.

xxxvi. Neuman, L. (2000). Educational research: Quantitative, qualitative, and mixed approaches. London: Sage.

xxxvii. Osuala, E. C. (1993). Introduction to research methodology. Onitsha, Nigeria: Africana-Fep Publishers Limited.

xxxviii. Piskorski, M. J. (2011). Social strategies that work. Harvard Business Review, 89(11), 116-122.

xxxix. Sarantakos, S. (1998). Social research (3rd ed.). Basingstoke, Hants: Palgrave Macmillan.

xl. Thurairaj, S., Hoon, E. P., Roy, S. S., \& Fong, P. W. (2015). Reflections of students' language usage in social networking sites: Making or marring academic English. Electronic Journal of E-Learning, 13(4), 302-316.

xli. Walsh, L. (2013). Number matters: The multimodality of Internet use as an indicator of the digital inequalities. Journal of Computer-Mediated Communication, 1(7), 303-318. 